3. HISTORIA DEL DERECHO EUROPEO 

Revista de Estudios Histórico-Jurídicos

[Sección Historia del Derecho Europeo]

XXXI (Valparaíso, Chile, 2009)

[pp. 199 - 216]

\title{
TRAS LA HUELLA DE LAS "PACTIONES ET STIPULATIONES" ROMANAS COMO MODOS DE CONSTITUCIÓN DE SERVIDUMBRES PREDIALES EN EL DERECHO HISTÓRICO ESPAÑOL Y ESPECIALMENTE EN EL CASO DE CATALUÑA
}

["Tracing the Roman "Pactiones et Stipulationes" as Forms of Constitution of Appurtenant Easements in the Spanish Historical Law and Specially in the Case of Catalonia"]

\author{
Rosa M. CARreño SÁNCHEZ* \\ Universidad de Gerona, España
}

\section{RESUMEN}

Las pactiones et stipulationes fueron el modo de constitución de las servidumbres que, conforme a Gai. 2,31, se aplicó en las provincias romanas en época clásica y que, posteriormente, se generalizaría en el Derecho romano posclásico $\mathrm{y}$, especialmente, en el Derecho justinianeo. Tras la caída del Imperio Romano de Occidente hasta producirse la recepción del Corpus iuris civilis en Europa, la suerte de las pactiones et stipulationes se encuentra plenamente marcada por la trayectoria que sigue este modo de constitución en el Derecho posclásico, pero sobre todo, por la compleja transformación que tiene lugar respecto de la stipulatio, desde época clásica, pasando por su tratamiento en la compilación justinianea, hasta su recepción de el Derecho bajo medieval. La huella que las pactiones et

\begin{abstract}
According to Gai. 2, 31, the pactiones et stipulationes were the normal method to constitute servitudes in the Roman provinces during the classical epoch. The use of this method of constitution became widespread in the post-classical Roman law and, especially, in the Justinian law. From the fall of the Western Roman Empire until the reception of the Corpus iuris civilis in Europe, the destiny of the pactiones et stipulationes is clearly determined by the trajectory of this method of constitution in the post-classical law, but above all, by the complex transformation of the stipulatio, from the classical epoch, through the Justinian compilation, until its reception in late medieval law. The trace left by the pactiones et stipulationes in Spanish historical law should be studied starting from the trans-
\end{abstract}

* Profesora asociada de Derecho romano en la Facultad de Derecho de la Universidad de Gerona. Dirección postal: Campus de Montilivi s/n, E-17071 Girona, España. Correo electrónico: rosamaria.carreno@udg.edu 
stipulationes romanas dejaron en el Derecho histórico español ha de ser estudiada partiendo de la transformación de la stipulatio y la impronta que ésta última fue dejando, a lo largo de los siglos, en la práctica documental notarial.

Palabras Clave: Pactiones et stipulationes - Servidumbres - Derecho histórico español. formation of stipulatio and the mark left by its transformation, along the centuries, in notarial documental practice.

Keywords: Pactiones et stipulationes Servitudes - Spanish Historical Law.

\section{INTRODUCCIÓN}

Gayo informa que en su época (mediados del siglo II d. C.), incluida en la que nosotros consideramos clásica del Derecho romano, en las provincias era posible constituir servidumbre mediante pacta y stipulationes (pactionibus et stipulationibus) ${ }^{1}$. El uso de este modo de constitución en el suelo provincial se explica por el especial régimen jurídico de éste último, que lo excluía del dominium ex Iure Quiritium de los particulares y lo hacía inaccesible a la mancipatio o la in iure cessio.

Su sencillez, el complejo, pero a la vez polivalente entramado de medios procesales con los que se vería tutelada la relación constituida pactionibus et stipulationibus, la influencia del Derecho provincial, así como la existencia de concretas situaciones sobre el suelo itálico, en las que no era posible el uso de los modos de constitución propios del ius civile, son los elementos básicos que han conducido a la doctrina a la eterna discusión sobre la posibilidad de que las pactiones et stipulationes, gestadas en ámbito provincial, se hubieran empleado, en plena época clásica, para la constitución de servidumbres sobre suelo itálico y hubieran dado lugar a las servidumbres constituidas tuitione praetoris o, dicho de otro modo y con carácter general, a la "servidumbre pretoria" 2 .

${ }^{1}$ Gai. 2,31: "Sed haec scilicet in Italicis praediis ita sunt, qui et ipsa praedia mancipationem et in iure cessionem recipiunt. Alioquin in provincialibus praediis sive quis usufructum sive ius eundi agendi aquamve ducendi vel altius tollendi aedes aut non tollendi, ne luminibus vicini officiatur, ceteraque similia iura constituere velit, pactionibus et stipulationibus id efficere potest; quia ne ipsa quidem praedia mancipationem, aut in iure cessionem recipiunt".

${ }^{2}$ V. gr.: PerozzI, Silvio, I modi pretorii d'acquisto delle servitù, en Rivista italiana per le scienze giuridiche 23 (1897), p. 3; KRÜGER, Hugo, Die prätorische Servitut (Münster, 1911); Albertario, Emilio, La protezione pretoria delle servitù, en Filangieri, 36 (1912), p. 207; Riccobono, Salvatore, "Dies" e "condicio" nella costituzione della servitù, en Tijdschrift voor Rechtsgeschiedenis 3 (1922), p. 333; RABEL, Ernst, Zu den sogennanten prätorischen Servituten, en Mèlanges Girard (Paris, 1923), II ("Droit privé et procédure"), p. 387; FrezZA, Paolo, Appunti esegetici in tema di modi pretori di costituzione di usufrutto e delle servitú prediali, en Studi economico-giuridici dell'Università di Cagliari 22 (1934), p. 84; MASCHI, Carlo Alberto, Contributi allo studio delle servitù pretorie, en Bulletino dell'Istituto di Diritto Romano 41 (1939), p. 274; BIONDI, Biondo, Le servitù prediale nel diritto romano (Milano, 1969), $\$ 35$ : "Servitù pretorie”; Grosso, Giuseppe, Le servitù prediale nel Diritto romano (Turín, 1969), p. 204. Más recientemente, LA Rosa, Franca, "Pactionibus et stipulationibus", en Labeo 40 (1994) 1, p. 27; y Maninno, Vincenzo, Conventio e voluntas nell'operatività delle servitù e come fundamento 
Con independencia de estas discusiones y a la aplicación o no de las pactiones et stipulationes más allá de las provincias en el Derecho romano clásico, no genera tantas dudas la amplia utilización de este modo de constitución en el Derecho posclásico y, especialmente, en Derecho justinianeo ${ }^{3}$.

El destino que aguardó a las pactiones et stipulationes tras la caída del Imperio romano de Occidente y al producirse la recepción del Derecho justinianeo mucho tiene que ver con la trayectoria que sigue este modo de constitución en el Derecho romano posclásico y, especialmente, estará marcado por la compleja transformación que sigue la stipulatio ya desde finales de la época clásica -transformación plenamente vinculada, además, a la figura del pactum-, hasta la forma en que ésta es tratada en la compilación justinianea y cómo se produce su recepción en Europa. Por este motivo, consideramos oportuno centrarnos, como punto de partida de esta contribución, en la evolución que se produce en torno a la figura de la stipulatio y observar cómo ésta afecta en lo que a la constitución de las servidumbres en las diferentes épocas se refiere.

Así pues, intentaremos en esta sede contribuir, dentro de las limitaciones propias de esta aportación, a dar noticia del destino que, a nuestro entender, aguardó a las pactiones et stipulationes, en un primer momento, tras la caída del Imperio romano de Occidente y, más tarde, tras la recepción del Corpus iuris civilis en Europa. Asimismo, hemos de advertir que, en muchas ocasiones debido a la falta de fuentes que corroboren nuestras conclusiones y el estado aun embrionario de nuestra investigación, no podemos pronunciarnos más allá de lo que constituye una mera hipótesis.

\section{CONSTITUCIÓN DE SERVIDUMBRES "PACTIONIBUS ET STIPULATIONIBUS” EN EL DERECHO ROMANO POSCLÁSICO}

Si en el Derecho romano clásico la diversidad de regímenes de los suelos itálico y provincial justificaba, asimismo, que los modos de constitución de las servidumbres fueran distintos, en el Derecho posclásico, al desaparecer progresivamente la distinción entre ambos tipos de suelo y la distinción entre res mancipi y nec mancipi -y con ella la de la mancipatio y la in iure cessio- ${ }^{4}$, amén de la gran influencia que ejerce el mundo provincial, es lógico que también sucumbiera la dualidad de regímenes de constitución de las servidumbres y se generalizara el uso de las pactiones et stipulationes.

Cabe, además, tener en cuenta las características propias del Derecho romano

della "servitus personae", en "Iuris vincula". Studi in onore di Mario Talamanca (Napoli, 2001), $\mathrm{V}$, p. 145. El posible uso de las pactiones et stipulationes para la constitución de servidumbres sobre suelo itálico, en época clásica, es una de las razones que la doctrina aduce para explicar su generalización en el derecho posterior y, especialmente, en el justinianeo.

${ }^{3}$ Kaser, Max, Das römische Privatrecht (2a edición, München, 1975), p. 300; Grosso, Giuseppe, cit. (n. 2.), pp. 226 ss.

${ }^{4}$ Capogrossi, Luigi, Proprietà e diritti reali. Usi e tutela della proprietà fondiaria nel Diritto romano (Roma, 1999), pp. 159 ss. MANINNO, Vincenzo, Conventio e voluntas nell'operatività delle servitù e come fundamento della "servitus personae", en "Iuris vincula". Studi in onore di Mario Talamanca (Napoli, 2001), V, p. 145. 
posclásico, especialmente en lo que se refiere a la vulgarización del Derecho, que comporta, entre otros aspectos, una relajación de los conceptos jurídicos del mundo clásico. Así, en lo que a nuestra materia atañe, parece haber desaparecido la rígida distinción clásica entre actos con eficacia real y actos con eficacia obligacional (téngase en cuenta, por ejemplo, la fusión que se da respecto de los diferentes tipos de legados) y, en cuanto a las servidumbres, el uso del término servitus parece hacerse en referencia, más que a la institución tal y como se conocía en el Derecho clásico, a limitaciones a la propiedad, concretamente respecto de la edificación, sobre todo en lo que se refiere a las distancias que deben dejarse entre los edificios, tema que es tratado por las constituciones imperiales de la épocas.

Si observamos la literatura jurídica posclásica, además, podemos ver cómo se han visto alterados algunos de los principios configuradores de las servidumbres propios del Derecho clásico, pero sin embargo, los textos de la época no nos informan claramente de cómo debían constituirse las servidumbres ${ }^{6}$.

Ante esta situación, resulta lógica la aseveración del profesor $\mathrm{Levy}^{7}$ cuando expresa que nuestro modo de constitución genera menos problemas interpretativos - a los romanistas- si es contemplado desde el punto de vista del Derecho posclásico, ya que desde la óptica del Derecho clásico, resulta mucho más difícil

\footnotetext{
${ }^{5}$ En este sentido, destaca el hecho de que la regulación de la época apenas se ocupa de las servidumbres prediales, aunque las necesidades que hicieron surgir en Roma esta institución continúan existiendo como es lógico. Las constituciones de la época regulan, más bien, aspectos relativos a la edificación, como en CTh. 4,24,1: "De servitute luminis vel aeris similiter constitutum est, ut inter privatorum fabricas decem pedes, inter publicas quindecim dimittantur". El texto habla de servitus luminis vel aeris, pero curioso resulta el hecho de que, a partir de esta constitución, la servidumbre no se constituye voluntariamente, como venía sucediendo hasta ahora, sino por mandato legal derivado de la regulación que se hace de la edificación. Referencias a otras servidumbres las hayamos, también a título de ejemplo, en CTh. 15,2 en relación al aquae ductus, pero en realidad esta regulación tiene que ver con el uso de acueductos públicos y se suele hablar de usus aquae. Esta regulación también afecta al uso de las vías públicas: entre otros, v. Grosso, Giuseppe, cit. (n. 2), p. 316; Franciosi, Gennaro, Studi sulle servitù prediali (Nápoles, 1967), pp. 126 y 140; Levy, Ernst, West Roman Vulgar Law. The Law of Property (Filadelfia, 1951), pp. 55 y 56; KASER, Max, cit. (n. 3), pp. 298 ss. (\$ 246); PACHECO, Francisco, Las servidumbres prediales en el derecho histórico español (Lleida, 1991), pp. 80 ss.

${ }^{6} \mathrm{Si}$ bien en Fr. Vat. 61, que parece recoger un fragmento de Ulpiano ad Sabinum, se habla de la constitución de usufructo tuitione praetoris sobre los predios provinciales, texto en el que muchos romanistas han querido ver una referencia a la constitución del usufructo pretorio $-\mathrm{y}$ por ende, también de la servidumbre pretoria- y concretamente, una referencia a su constitución pactionibus et stipulationibus: "Item. Amitti autem usum fructum capitis minutione constat nec solum usum fructum, sed etiam actionem de usu fructu: scilicet si Titio usum fructum [laguna] testamento vel per fideicommissum lego vel relinquo et die eius cedente is capite minutus est [laguna] agere non potest. Et parvi refert, utrum iure sit constitutus usus fructus an vero tuitione praetoris; proinde usus fructus licet in fundo stipendiario vel tributario, item in fundo vectigali vel superficie non iure constitutus capitis minutione amittitur [laguna] capitis minutio extinguit usum fructum [laguna]". El mismo texto de Ulpiano reaparece en época justinianea en D. 7,4,1 pr.

${ }^{7}$ LeVy, Ernst, cit. (n. 5), pp. 57 y 198.
} 
entender cómo con el concurso de la stipulatio, figura que tiene efectos meramente obligacionales, es posible constituir una servidumbre.

Si partimos de la idea de que, en época posclásica, no se establece una rígida distinción entre actos con eficacia real u obligacional, y dadas las circunstancias y a la posterior inclusión de las pactiones et stipulationes en las Institutiones justinianeas, resulta completamente posible, que se empleara con carácter general este modo de constitución, cuya estructura, además, presentaba la ventaja para las partes de poder configurar la servidumbre que querían constituir de acuerdo a sus especiales necesidades e incluso decidir si lo que querían constituir realmente era una servidumbre o una relación obligatoria -lo que parece poder determinarse a la luz de los acuerdos concluidos por las partes-. Ahora bien y a diferencia de lo que debía suceder en época clásica, este modo de constitución aparece, en esta época y en su conjunto, como un acto escrito.

Nos parece a su vez verosímil que, en época medieval y hasta la recepción de Derecho justinianeo, las soluciones del Derecho posclásico en esta materia fueran las que se continuaran aplicando y que, consecuentemente, las pactiones et stipulationes continuaran empleándose para constituir las servidumbres. El destino que aguarda a este modo de constitución vendrá marcado por lo que ocurre con la stipulatio en la evolución jurídica posterior.

\section{LA TRANSFORMACIÓN DE LA “STIPULATIO" Y EL TRÁNSITO DE LA FORMA ORAL AL DOCUMENTO}

La stipulatio romana, sufre a lo largo de los siglos una transformación radical, que la hará pasar de ser un acto eminentemente oral, a un acto escrito.

Este contrato verbal, auténtica pieza clave en el engranaje del sistema contractual romano y utilizado para las más diversas finalidades en virtud de su carácter polivalente capaz de conferir fuerza y eficacia jurídica a cualquier tipo de acuer$\mathrm{do}^{8}$, en el Derecho clásico tiene, como principal característica, su sujeción a una determinada forma: el intercambio de pregunta y respuesta en unidad de acto, que puede tener lugar de modo oral u oral-gestual.

La observancia de estos requisitos formales exigidos -oralidad, presencia de las partes, unidad de acto y la congruencia- dará lugar a que se produzcan los efectos propios de aquel negocio, con independencia de la voluntas de las partes o de la causa negocial.

$\mathrm{Al}$ convertirse la stipulatio en una institución iuris gentium y, por lo tanto, hacerse accesible a los peregrinos, se admite que pregunta y respuesta puedan formularse en otras lenguas que no sean el latín (cfr. Gai. 3,92 y 93) ${ }^{9}$ y, a su vez,

${ }^{8}$ Véase, a título de ejemplo, la enumeración de las múltiples finalidades para las que se emplea la stipulatio en Linares Pineda, José L., "Stipulatio", en Materiales para el estudio del Derecho. Derecho romano de "Portal del Derecho" SA/IUSTEL (www.iustel.com), también disponible en los materiales "on line" de la página web del grupo de investigación de la UdG "Història de la ciència jurídica": http://web2.udg.es/hcj.

${ }^{9}$ WACKE, Andreas, El pluralismo lingüístico y su reglamentación juridica en el imperio romano, Seminarios Complutenses de Derecho Romano 11 (1999), pp. 117 ss. 
esta institución entra en contacto y recibe la influencia del Derecho de otros pueblos.

En lo que se refiere a la aparición del documento junto a la stipulatio ${ }^{10}$, en un primer momento, el documento cumple con una función meramente probatoria de la obligación u obligaciones, que continúan surgiendo, sin embargo, de la celebración del acto oral con los requisitos que hemos mencionado anteriormente. El escrito, en esta época, sirve para documentar a posteriori aquello que las partes han acordado, se plasma en el documento la conventio preliminar que ha sido volcada en la forma de la stipulatio. De la redacción del documento, que sigue la forma de las testationes o bien del chirographum ${ }^{11}$, empezarán a ocuparse los tabelliones, auténticos profesionales con conocimientos jurídicos, cuya actividad cada vez será mayor ${ }^{12}$.

Al complicarse cada vez más las relaciones comerciales, la práctica hizo necesaria la redacción del documento con los acuerdos a que llegaban las partes antes de la misma celebración de la stipulatio. Ésta se celebra posteriormente y se refiere al documento en el que se recogen los acuerdos. Lo que resulta destacable es que, en este momento, la stipulatio da eficacia a una declaración de voluntad redactada por escrito y con carácter previo a su realización. Pero igualmente, en esta época, las consecuencias jurídicas se derivan de la oralidad y no del documento.

$\mathrm{Al}$ entrar en contacto la stipulatio del ius gentium con el Derecho de otros pueblos, es normal que recibiera el influjo de las costumbres y prácticas nego-

\footnotetext{
${ }^{10} \mathrm{El}$ uso del documento junto a la stipulatio, se habría producido ya desde época republicana, para facilitar el intercambio de pregunta y respuesta, haciendo una remisión a aquello que las partes habían acordado y puesto por escrito -"Haec, quae supra scripta sunt, fierildari?"-, como ocurre en el famoso fragmento de Paulo de D. 17,2,71 pr. o en el fragmento del mismo jurista de D. 45,1,140 pr: "Pluribus rebus praepositis, ita stipulatio facta est: 'ea omnia, quae supra scripta sunt, dari?' propius est, ut tot stipulationes, quot res sint". Aunque en este caso se haga una remisión al documento, la obligación surge, no obstante, de la pregunta y respuesta posteriores sobre lo que ese documento contiene y no del propio documento.

${ }^{11}$ En cuanto a la forma del documento, se distingue entre la forma objetiva y subjetiva. La primera es la propia del mundo romano, se denomina testatio y de acuerdo a esta forma se recoge de manera objetiva en el documento los comportamientos de las partes que tienen relevancia jurídica y las declaraciones negociales. La prueba de los hechos recogidos en la testatio se ve garantizada por la presencia, generalmente, de 7 testigos que son los que cierran el documento con su sello. La forma subjetiva, en cambio, provendría del mundo griego y es mucho más reciente, se denomina chirographum, lo redacta el emitente en primera persona. La fuerza probatoria de los hechos recogidos deriva de la autografía de la persona contra quien se constituye en prueba el documento o de la persona de confianza de ésta última. Por su estructura sólo puede recoger declaraciones negociales. V. TaLAmanca, Mario, voz: "Documento e documentazione", en Enciclopedia del Diritto (Milano, Giuffrè, 1964), XIII, pp. 548 ss.

${ }^{12}$ Sobre el tabellio romano existe una abundante bibliografía de la que cabe destacar: AnKum, Hans A., Les tabellions romains, ancêtres directs des notaires modernes, en Atlas du Notariat. Le notariat dans le monde. Huit siècles de notariat latin-Quatre décennies d'union internationale, Ars Notariatus XLII (separata); D'Ors, Álvaro, Documentos y notarios en el derecho romano post-clásico, en Centenario de la Ley del Notariado (Madrid, 1964), I, p. 129.; Fernández De Buján, Antonio, A propósito del oficio de tabellio como jurista práctico en la experiencia jurídica romana, en Liber amicorum Juan Miquel. Estudios romanisticos con motivo de su emeritazgo (Barcelona, 2006), p. 309.
} 
ciales de estos, y que allí donde tradicionalmente se solían documentar los actos y negocios que realizaban los particulares, se hubiera continuado poniendo por escrito estos actos, haciendo constar en el documento que la stipulatio se había realizado, para así cumplir con las exigencias del Derecho romano (cláusulas estipulatorias: interrogatus spopondi/t). Esto habría tenido lugar, sobre todo, a partir del 212, cuando la Constitutio Antoniniana concede la ciudadanía romana a todos los habitantes del Imperio ${ }^{13}$.

Debido seguramente a la influencia de las prácticas que se dan en las provincias, a finales de la época clásica, la jurisprudencia de la época de los Severos admite que si resulta del documento probatorio la promesa del deudor, no puede ponerse en duda que se hubiera producido la interrogatio, el documento deviene prueba misma (presunción) de que tuvo lugar la stipulatio. Para algunos autores, en este momento es cuando empieza la denominada "degeneración posclásica" de la stipulatio, que sin embargo, puede ser contemplada desde otro punto de vista menos peyorativo como "evolución" de la stipulatio. Esta evolución traería causa, no sólo de la influencia de la práctica documental que se da en las provincias, sino que también, del rol que atribuía la jurisprudencia, ya desde la época clásica, a la voluntas y al documento probatorio y, en definitiva, a una visión no tan "estricta" de la forma de la stipulatio ${ }^{14}$.

La Constitución del emperador León de 472 (CI. 8, 37, 10) ${ }^{15}$, implica un paso más en este camino, al permitir prescindir del intercambio de formas orales predeterminadas. Elimina el formalismo, pero no la oralidad, da eficacia a todas las estipulaciones con independencia de los verba utilizados, stipulationes que suelen presentar la forma escrita. Este documento es denominado cautio, instrumentum, chirographum, scriptura, subscriptio, etc.

En época justinianea, siguiendo los pasos del emperador León, Justiniano atribuye al documento la facultad de dar prueba de la celebración de la estipulación,

${ }^{13}$ Los rescripta de la época de los Severos y especialmente de la de Diocleciano dan muestra de los intentos frustrados de estos emperadores por defender en Oriente el hecho de que la obligación surge de la stipulatio oralmente celebrada y no de la redacción de un documento que sólo puede tener una eficacia probatoria (cfr. CI. 4,2,12; 14, 64,3). Tras la concesión de la ciudadanía en el 212 a todos los habitantes del Imperio, más que imponerse el derecho romano en todos los rincones del Imperio, éste convive con los derechos de los diferentes pueblos y se influyen mutuamente, las dificultades que ello ocasiona pueden verse claramente en los rescripta de esta época, como es el caso de la stipulatio, los habitantes de las provincias orientales acaban aplicando su propio derecho, pero disfrazándolo o adecuándolo en la medida de lo posible al derecho romano. Buena cuenta de ello da el profesor MiTTEIs, Ludwig, Reichsrecht und Volksrecht in den östlichen Provinzen des römischen Kaiserreichs (Leipzig, 1891), hemos consultado la edición facsímil de Georg Olms de 1984, y, entre nosotros, destaca la conferencia de Álvarez, Ursicino, Los derechos provinciales romanos y el problema del derecho foral español, en Anuario de Derecho civil 2 (octubre-diciembre, 1948) 1, pp. 1330 a 1344, en el que se compara la cuestión del derecho foral español (en la época previa a las Compilaciones de derecho foral) y la experiencia romana sobre la unidad/pluralidad jurídica.

${ }^{14}$ En este sentido, véase: KNÜTEL, Rolf, "Stipulatio" und "pacta", en Festschrift für Max Kaser zum 70. Geburtstag (München, 1976), pp. 201 ss.

${ }^{15}$ CI. 8,37,10: "Omnes stipulationes, etiamsi non sollemnibus vel directis, sed quibuscumque verbis pro consensu contrahentium compositae sint, legibus cognitae suam habeant firmitatem". 
a menos que lo contrario se pueda demostrar por no haber estado presentes las partes y no haberse podido realizar, por tanto, el acto oral (Constitución del año 531, CI. 8,37,14,2 $\left.{ }^{16}\right)$. No obstante, con ello el emperador no persigue la realización del acto oral en sí -lo que en la práctica de su época ya no debía producirse con demasiada asiduidad-, sino más bien asegurar la presencia de las partes que concluyen el negocio. Además, con anterioridad, a través de una Constitución del año 528 (CI. 4,21,17 ${ }^{17}$ ), concede autonomía y eficacia al escrito, que adquiere importancia sobre el acto oral. Así, si las partes han decidido poner por escrito el negocio que quieren celebrar, éste no tiene validez hasta que no se haya puesto en limpio y sea confirmado con las firmas de las partes y, en el caso de intervenir el tabellio, es necesario que se produzca la completio ${ }^{18}$. El documento se ha convertido, ya en esta época, en dispositivo.

\section{EL USO DE LA “STIPULATIO” DURANTE LA ALTA EDAD MEDIA Y SU RECEPCIÓN EN EL DERECHO BAJO MEDIEVAL}

El uso de la stipulatio durante toda la época medieval y el valor definitivo del documento son hechos que han subrayado, sobre todo entre nosotros, Núñez Lagos y Arias Bonet, al estudiar la recepción de la stipulatio en la Baja Edad Media, en las Partidas ${ }^{19}$.

La estipulación medieval aparece documentada por escrito, pero no es un reflejo exacto del acto oral, pues en el escrito se recoge ahora la narración indirecta, abreviada, objetiva e impersonal de todo lo acordado. Los verba oblicua sustituyen a los verba directa: no se ponen por escrito todas y cada una de las

${ }^{16}$ CI. 8,37,14 2: "Et si inter praesentes partes res acta esse dicitur, et hoc esse credendum, si tamen in eadem civitate utraque persona in eo die commanet, in quo huiusmodi instrumentum scriptum est, nisi is, qui dicit sese vel adversarium abesse, liquidis ac manifestissimis probationibus et melius quidem, si per scripturam, sed saltem per testes undique idoneos et omni exceptione maiores ostenderit sese vel adversarium suum eo die civitate afuisse: sed huiusmodi scripturas propter utilitatem contrahentium esse credendas".

${ }^{17}$ CI. 4,21,17: "Contractus venditionum vel permutationum vel donationum, quas intimari non est necessarium, dationis etiam arrarum vel alterius cuiuscumque causae, illos tamen, quos in scriptis fieri placuit, transactionum etiam, quas instrumento recipi convenit, non aliter vires habere sancimus, nisi instrumenta in mundum recepta subscriptionibusque partium confirmata et, si per tabellionem conscribantur, etiam ab ipso completa et postremo a partibus absoluta sint, ut nulli liceat prius, quam haec ita processerint, vel a scheda conscripta, licet litteras unius partis vel ambarum habeat, vel ab ipso mundo, quod necdum est impletum et absolutum, aliquod ius sibi ex eodem contractu vel transactione vindicare: adeo ut nec illud in huiusmodi venditionibus liceat dicere, quod pretio statuto necessitas venditori imponitur vel contractum venditionis perficere vel id quod emptoris interest ei persolvere".

${ }^{18}$ Justiniano regula con especial detalle el documento tabeliónico (instrumentum publice confectum), de su regulación destaca la Constitución de 528 (CI. 4,21,17), así como las Nov. Iust. 44 (537), 73 y 76 (538), que serán de gran influencia en la regulación del notariado tras la recepción del Corpus iuris civilis.

${ }^{19}$ Núñez Lagos, Rafael, La estipulación en las Partidas y en el Ordenamiento de Alcalá (Madrid, Real Academia de Jurisprudencia y Legislación, 1950); ARIAs BONET, Juan Antonio, Recepción de las formas estipulatorias en la Baja Edad Media. Un estudio sobre las "promisiones" de las Siete Partidas, en Boletim da Faculdade de Direito de Coimbra 42 (1967), pp. 285 a 334. 
preguntas que formula el acreedor y las respuestas a cada una de éstas por parte del deudor. En el escrito, se incorpora, al principio o al final de esa redacción indirecta, una estipulación especial que da eficacia al todo (stipulanti spopondit; cum stipulatione et promisione interposita; cum stipulatione subiecta; cum stipulatione subnixa). En muchas ocasiones, para el caso del incumplimiento, a la stipulatio specialis la acompañaba una stipulatio poenae. Aparece también la denominada stipulatio eliptica, en la que la narración aparece en primera persona y de manera unilateral, posibilitando de este modo la contratación entre ausentes.

En lo que se refiere a la recepción de la stipulatio de la compilación justinianea en nuestro Derecho histórico, como avanzábamos, ésta ha sido estudiada por Núñez Lagos y Arias Bonet, en el caso de Castilla y en relación con las Partidas. Con carácter general y de acuerdo al profesor Coing ${ }^{20}$, la recepción de la stipulatio da lugar a que sea estudiada como un contrato especial a tener en cuenta, sobre todo, en la práctica notarial. La introducción de cláusulas estipulatorias (v. gr. stipulationibus intervenientibus) o la utilización de verbos como "promittere" convertían a los acuerdos en accionables. La stipulatio es concebida ahora como vestimentum pacti, a diferencia del antiguo Derecho romano, en el que es una forma de obligarse, en principio, desconectada de la voluntad de las partes, que era un presupuesto externo y previo a la stipulatio.

La recepción de la stipulatio en Castilla se produce a través de las Siete Partidas, concretamente a partir de la Partida V, en su título $11^{\circ}$, y se denomina "promisión". Es definida por la ley $1^{a}$ de dicho título como: "otorgamiento que fazen los omes unos con otros, por palabras e con intención de obligarse, auiniendose sobre alguna cosa cierta, que deuen dar o fazer, vnos a otros. E tiene grand pro a las gentes, quando es fecha derechamente, e con razon. Ca asseguran los omes, los vnos a los otros, lo que prometen, e son tenudos de lo guardar".

La promission se realiza: "estando presentes amos los que quieren fazer el pleyto de la promission, e diziendo el vno al otro: Prometesme, de dar, o de fazer tal cosa; diziendola señaladamente: e el otro respondiendo, que si promete, o que lo otorga de cumplir. E respondiendo por estas palabras, o por otras semejantes dellas, finca porende obligado, e es tenudo de cumplir lo que otorga, o promete de dar, o de fazer: e maguer los que fazen tal pleyto, non fablasen amos vn lenguaje, como si el uno fablase latino, e el otro arauigo, vale la prmission; solamente, que se entienda el vno al otro, sobre la pregunta, e respuesta. Esso mismo dezimos que seria, si fuessen amos de dos lenguajes, maguer non lo entediesse el vno al otro, e estando amos presentes firmassen, el pleyto entre si por alguna trujamania, en que se aueniessen amos a dos, valdria la promission, tambien como si se entendiessen los que fazen el pleyto".

Según Núñez Lagos, esta construcción de la stipulatio de la Partida V recoge en realidad una concepción que denomina "erudita o arcaica", que provendría de Donellus y Cuiacius y que nada tiene que ver con la práctica castellana de la época. De hecho pone en duda la existencia de cláusulas estipulatorias o promisiones expresas al no hallar ningún rastro de éstas en las colecciones diplomáticas de Hinojosa, P. Luciano Serrano ni de J. González. La única excepción sería

\footnotetext{
${ }^{20}$ CoIng, Helmut, Europäisches Privatrecht (München, 1985), I, pp. 480 ss.
} 
un documento de 1258, que aparece recogido en la colección de documentos procedentes de la Catedral de Valladolid, en que se hace referencia expresa a la realización de una estipulación, sin embargo al ser un documento redactado por un scriniarius de la Curia romana, la mención ya no resulta tan significativa, pues en los territorios italianos de dominación longobarda no parece tan rara la persistencia de la stipulatio ${ }^{21}$. Así pues, y como indica Arias Bonet, existe en cuanto a la Partida V "un claro divorcio entre ley y documento".

La "construcción erudita" de la estipulación se contrapone a la "construcción popular y actual”, mucho más acorde con las prácticas documentales de la época y que se refleja en la partida III. Esta partida recoge la formulación popular de la estipulación que se encuentra en los formularios notariales. La ley $1^{\circ}$ del título $18^{\circ}$ de esta Partida distingue entre los documentos públicos y privados. Entre los documentos públicos sitúa los instrumentos públicos, entre los cuales se encuentran la nota o dictum y la charta o mundum. Los modelos que contienen la stipulatio en su "construcción popular" son las cartas de los instrumentos públicos ${ }^{22}$, lo que claramente se desprende de la observación de las escrituras notariales que se conservan de esa época y de los propios ejemplos que la Partida ofrece al establecer cómo deben redactarse las chartas respecto de diferentes negocios ${ }^{23}$.

A nuestro entender, la partida III, al regular las chartas, sería el reflejo del camino que habría seguido la stipulatio desde el Derecho posclásico romano hasta la Baja Edad Media a través de la práctica documental y se contrapone a la stipulatio de la compilación justinianea -cuya recepción en Castilla tiene lugar a través de la Partida V en las promissiones-, en la que Justiniano intenta plasmar los rasgos más destacados de la stipulatio del Derecho clásico introduciendo, sin embargo, las oportunas excepciones para adecuar la stipulatio del Derecho clásico a la práctica que se da en la realidad en su época y que no puede obviar ${ }^{24}$.

${ }^{21}$ Núñez Lagos, Rafael, cit. (n.19), p. 47 ss.; Arias Bonet, Juan Antonio, cit. (n. 19), p. 287 ss.

${ }^{22}$ En contra de esta idea se muestra Arias Bonet, quien entiende que, en realidad, las leyes de la Partida III a que se refiere Núñez Lagos tan sólo hacen hincapié en los diferentes medios de prueba que se pueden aportar en juicio, entre ellos los documentos privados redactados por el deudor siempre que conste la causa de la deuda, que puede consistir en cualquiera de los contratos típicos, entre estas causas puede incluirse a la promission, ARIAS BONET, Juan Antonio, cit. (n. 19), p. 297. Para este autor, más que la contradicción entre las Partidas III y $\mathrm{V}$, que defiende Núñez Lagos, entiende que existe un contraste entre la detallada regulación que recoge la partida $\mathrm{V}$ y el silencio absoluto que en torno a la promission se produce en la Partida III.

${ }^{23}$ Las leyes $56^{\mathrm{a}}$ a $66^{\mathrm{a}}$ del tít. $18^{\circ}$, P. III recogen fórmulas que presentan la stipulatio specialis relativas a la compraventa; la ley $67^{\mathrm{a}}$ a la permuta; la ley $68^{\mathrm{a}}$ al feudo; la ley $69^{\mathrm{a}}$ al censo; la $70^{\mathrm{a}}$ al mutuo; la ley $71^{\mathrm{a}}$ al comodato; la ley $72^{\mathrm{a}}$ al depósito, las leyes $73^{\mathrm{a}}$ y $74^{\mathrm{a}}$ al arrendamiento; la ley $75^{\mathrm{a}}$ al trabajo (prestación de servicios); la ley $76^{\mathrm{a}}$ al arrendamiento de semovientes; la ley $77^{a}$ al fletamento de nave; la ley $78^{a}$ a la compañía (sociedad); la ley 79a a la aparecería; la ley $80^{\mathrm{a}}$ a la partición de la herencia; la ley $81^{\mathrm{a}}$ a cartas de pago (condonación de deuda); la ley $8^{\mathrm{a}}$ a la carta de paz; la ley $83^{\mathrm{a}}$ a la carta de tregua; las leyes $84^{\mathrm{a}}$ y $85^{\mathrm{a}}$ a los esponsales; la ley $86^{\mathrm{a}}$ a la dote; la ley $87^{\text {a }}$ a la donación y a las arras; la ley $88^{\mathrm{a}}$ a la entrada en una orden religiosa; la ley $89^{\mathrm{a}}$ al vasallaje; la ley $90^{\mathrm{a}}$ a la manumisión y la ley $106^{\mathrm{a}}$ sobre el compromiso.

${ }^{24}$ Kaser, Max, cit. (n. 2), p. 381. 
Se debe tener en cuenta, además, que la Partida III está claramente influida por la regulación justinianea del tabellio y del documento tabeliónico. Es por tanto esta construcción popular o actual de la Partida III a que se refiere Núñez Lagos la que tendrá consecuencias respecto de la constitución de las servidumbres y la que debemos tener en cuenta para ver la trayectoria que siguen nuestras pactiones et stipulationes.

\section{LA CONSTITUCIÓN DE SERVIDUMBRES "PACTIONIBUS ET STIPULATIONIBUS” EN ÉPOCA VISIGODA Y ALGUNAS REFERENCIAS A LA CONSTITUCIÓN EN ÉPOCA MEDIEVAL}

Antes de tratar la constitución de servidumbres en el Derecho bajo medieval y a la recepción, en esta materia, del Corpus iuris civilis, entendemos necesaria una breve referencia a la constitución de las servidumbres en la época visigoda y en la Alta Edad Media, entroncando con lo que hemos expuesto anteriormente sobre la constitución de servidumbres en el Derecho posclásico romano.

Una característica general de la época visigoda es la continuidad de la tradición jurídica romana, concretamente, de la del Derecho posclásico-vulgar. En la España visigoda, en la práctica, continúa aplicándose el Derecho romano posclásico-vulgar que convive con las costumbres germánicas y con la legislación de los reyes visigodos.

En concreto, en esta época regirían, en cuanto al Derecho romano, las colecciones de constituciones imperiales de los siglos III y IV, es decir, el Codex Gregorianus, el Hermogenianus y el Codex Theodosianus, que recogen, como mencionábamos al inicio, sobre todo, constituciones en materia de edificación o de uso de acueductos públicos. También se estarían aplicando la literatura jurídica aparecida en época posclásica, especialmente los Fragmenta Vaticana.

Este Derecho romano posclásico-vulgar convive, además, con las costumbres del Derecho germánico, que aún siendo mucho más elemental, influye sobre el primero.

Finalmente encontramos la legislación visigoda, que encuentra sus fuentes, a su vez, en el Derecho romano posclásico.

En lo que a la materia de las servidumbres se refiere, la legislación visigoda $y$, de acuerdo al profesor Pacheco, presenta las mismas características que hemos expresado en cuanto al Derecho romano posclásico-vulgar, esto es: desfiguración y desintegración de los iura posclásicos ("Breviario de Alarico") o ignorancia de las servidumbres como tal institución (paralelismo entre el Codex Theodosianus y el llamado "Código de Eurico" y el Liber Iudiciorum), sin que esto implique que las necesidades que cubren las servidumbres hayan desaparecido, sino que estas necesidades han debido encontrar respuesta en otros remedios diferentes a las servidumbres romanas. Aunque cabe destacar que la falta de documentos de aplicación del Derecho pertenecientes a esta época, dificultan el estudio de la materia y, por tanto, hace que sólo podamos pronunciarnos en base a hipótesis ${ }^{25}$.

${ }^{25}$ Francisco L. PACHeCO, cit. (n. 5), pp. 89 y ss. Aunque no resulte totalmente comparable con la situación que se vive en la Península Ibérica, sí es destacable la existencia en la Italia 
Cabe destacar, por otra parte, el absoluto silencio que guarda la legislación visigoda en cuanto a la constitución de las servidumbres en esta época: el "Breviario de Alarico" únicamente hace referencia al transcurso del tiempo como modo de adquisición de las servidumbres de saca de agua y de acueducto, basándose en las PS. 1,17,2: "Servitus hauriendae aquae vel ducendae bienio omisa intercidit, et bienio usurpata recipitur". Pero cabe preguntarse qué sucede con el resto de modos de constitución que se aplicaban en el Derecho posclásico, así como respecto del resto de servidumbres sobre las que la legislación visigoda no se pronuncia. Si partimos de la idea de continuidad de la tradición del Derecho romano posclásico-vulgar, sobre todo desde el punto de vista de la práctica notarial, así como la subsistencia de la stipulatio en esta época ${ }^{26}$, podemos llegar a concluir que debieron continuar empleándose las pactiones et stipulationes al igual que sucedía en el Derecho posclásico, junto a la longi temporis praescriptio. Aunque como expresábamos, no se trata más que de una hipótesis, porque no contamos con textos que nos lo confirmen ${ }^{27}$.

\section{CONSTITUCIÓN "PACTIONIBUS ET STIPULATIONIBUS" DE LAS SERVIDUMBRES PREDIALES DE ACUERDO CON INST. 2,3,2 Y RECEPCIÓN DEL DERECHO JUSTINIANEO}

En el Derecho justinianeo, las pactiones et stipulationes se convierten en el modo de constitución inter vivos de las servidumbres prediales por excelencia. Informa al respecto Inst. 2,3,2: "Ideo autem hae servitutes praediorum appellantur, quoniam sine praediis constitui non possunt. Nemo enim potest servitutem adquirere urbani vel rustici praedii, nisi qui habet praedium, nec quisquam debere, nisi qui habet praediam. Si quis velit vicino aliquod ius constituere, pactionibus atque stipulationibus id efficere debet. Potest etiam in testamento quis heredem suum damnare, ne altius aedes tollat, ne luminibus aedium vicini officiat: vel ut patiatur eum tignum in parietem immittere vel stillicidium habere: vel ut patiatur eum per fundum ire, agere aquamve ex eo ducere".

El fragmento de las Institutiones justinianeas guarda una clara semejanza con el de las Institutiones de Gayo (2,31), que trata de la constitución de las servidumbres prediales en las provincias.

Tras desaparecer la distinción entre suelo provincial e itálico y al desaparecer la mancipatio y la in iure cessio, Justiniano recoge en su compilación un modo de constitución que se había gestado en las provincias y que, las propias circunstancias,

alto medieval de documentos relativos a la constitución de servidumbres y cuyo contenido recuerda claramente a las pactiones et stipulationes romanas, sobre todo si las comparamos con la estructura que les atribuye Teófilo en su Paráfrasis a Inst. 2,3,2, pues dicha documentación recoge, además de los acuerdos de las partes relativos a la servidumbre que se quiere constituir, al igual que en Derecho romano, que no se impedirá el ejercicio o disfrute de la servidumbre por parte del constituyente y de sus herederos y se promete el pago de una pena para el caso contrario.

${ }^{26}$ En este sentido parece que existen claras muestras en las fórmulas visigótico-romanas de la subsistencia de la estipulación, Rafael, NúN̄EZ LAGOS, cit. (n. 19), p. 42.

${ }^{27}$ Ernst Levy, cit. (n. 5), p. 57, 58 y 200; PACHeCO, Francisco, cit. (n. 5), p. 109. 
habían dado lugar a que se convirtiera en el modo de constitución de las servidumbres prediales generalmente utilizado. $\mathrm{Al}$ reconocer las pactiones et stipulationes como modo de constitución inter vivos de las servidumbres prediales, Justiniano no hace más que reconocer lo que ya era una realidad en la práctica.

Teófilo, en su Paraphrasis, desarrolla el fragmento de las Instituciones justinianeas, reproducimos a continuación el texto en la versión en latín de Ferrini: "Qui vicino velit ius aliquod constituere pactionibus et stipulationibus id eficere potest. Pacto enim facto de servitute constituenda, is cui ea cedenda est ita stipulatur: spondesne cessam servitutem servare? Sin autem minus, spondesne dare mihi poenae nomine aureos centum?'28.

La recepción de las pactiones et stipulationes en la Baja Edad Media está íntimamente relacionada, por una parte, con la recepción de la stipulatio de la compilación justinianea, y por otra parte, con la evolución que ha sufrido la stipulatio desde el punto de vista de la práctica documental notarial.

Para estudiar cómo se produce la recepción del Derecho romano en cuanto a la constitución de servidumbres prediales, nos referiremos a las Siete Partidas ${ }^{29}$ para el caso de Castilla, debido a la importancia que reviste esta obra legislativa, sobre todo en vistas a la futura codificación del Derecho privado y, en el caso de Cataluña, nos referiremos especialmente a las Ordinacions de Sanctacilia, ya que constituyen un auténtico tratado de las relaciones de vecindad en el s. XIV y además acabaron aplicándose de manera general a toda Cataluña, exceptuando Tortosa -aunque las mismas normas que contienen las Ordinacions en materia de constitución de servidumbres suelen repetirse similarmente en el resto de colecciones de costums de la época, como es el caso de las Costums de la ciutat $i$ diòcesi de Girona.

\section{La constitución de servidumbres prediales en las "Partidas".}

La regulación relativa a las servidumbres prediales se encuentra contenida en la partida III, en los títulos $31^{\circ}$ y $32^{\circ}$ y recoge, a grandes rasgos, la configuración de las servidumbres del Derecho romano justinianeo.

En lo que a la constitución y adquisición de las servidumbres prediales se refiere, de acuerdo a la ley $14^{\mathrm{a}}$ del título $31^{\circ}$, las servidumbres se constituyen: "por otorgamiento que fazen aquellos cuyas son las cosas, otorgando de su voluntad seruidumbre en ellas a otros, por fazerles amor, o por precio que reciben dellos. La segunda [manera] es, la que fazen los omes en sus testamentos... La tercera es, quando ganan los omes seruidumbres en casas, o en heredamientos, por uso de tiempo..."

Nos interesa especialmente, teniendo en cuenta el objeto de nuestro estudio, la constitución a través de "otorgamiento de voluntad". No nos referiremos, por tanto, a la constitución mediante testamento o a su adquisición por usucapión.

La constitución de servidumbres, con arreglo al "otorgamiento de voluntad”,

\footnotetext{
${ }^{28}$ Ferrini, Contardo, Institutionum Graeca Paraphrasis (reimpresión Aalen, Scientia, 1967).

${ }^{29}$ Para estudiar las disposiciones de las Siete Partidas en materia de servidumbres -así como en referencia a la stipulatio-, hemos utilizado la edición de Sanponts y Barba, Martí d'Eixalà y Ferrer y Subirana de 1843.
} 
tendrá lugar, en base a un acuerdo de voluntades o contrato, de manera gratuita (“por fazerles amor") o bien onerosa ("por precio que reciben dellos").

Esta constitución convencional normalmente se recogerá en la carta, si bien no es obligatorio acudir a la documentación escrita, el documento redactado por un escribano público tiene claras ventajas en cuanto que genera fe sobre el acto que contiene (cfr. las leyes $115^{\circ}$ a $118^{\mathrm{a}}$, tít. $18^{\circ}$, part. III).

La constitución de las servidumbres, en cualquier caso, no tiene lugar a través de la simple promisión, pues no implica la constitución de la servidumbre en sí, sino que, como mucho, permitiría reclamar a través de una acción personal la constitución de dicha servidumbre (daría lugar, por tanto, a un derecho a la servidumbre, pero no a la servidumbre misma $)^{30}$ al igual que sucedería con la stipulatio justinianea ${ }^{31}$.

Para la constitución efectiva de la servidumbre, además del contrato, y por influencia de las normas relativas a la adquisición de la propiedad, es necesario transmitir la posesión (o cuasi-posesión), lo que tiene lugar, en el caso concreto de las servidumbres y al no ser posible la tradición de éstas por su propia naturaleza, a través de la introducción del propietario del predio dominante en el predio sirviente, o que el titular de la servidumbre ejercite su contenido con scientia et patientia del constituyente. La carta también daría fe de la transmisión de la cuasiposesión. Esta doctrina proviene de la compilación justinianea: ad exemplum, de D. $8,1,20 ; 8,6,9$ pr. ó CI. $3,34,3^{32}$.

${ }^{30}$ Caepolla, Bartholomaeus, Tractatus de servitutibus, tam urbanorum, quam rusticorum praediorum, cap. $21^{\circ}$ (Lausana, 1764), p. 55, refleja la discusión sobre si las promissiones por sí mismas permiten la constitución de servidumbres: "Promissione an servitus acquiratur? [...]. Dic quod per promissionem tantum non acquiratur servitus, nisi realiter constituatur? Quia talis sola promissio non constituit jus in re, hoc est, in servitute, sed jus ad rem".

${ }^{31}$ En el derecho romano justinianeo, tal y como se desprende de la THEOPh., Pararphr. a Inst. 2,3,2, se entiende constituida la servidumbre en tanto que existe un pacto y que éste es acompañado por una stipulatio de ejercicio por la que el constituyente promete no impedir ni él ni sus herederos el ejercicio de dicha servidumbre. La stipulatio nos permite conocer el acuerdo a través del cual las partes constituirían la servidumbre de acuerdo a sus especiales necesidades, pero su función es la de garantizar el uso de la servidumbre por parte de su titular y de sus herederos, con lo cual se entendería adquirida la posesión (o cuasi-posesión) sobre la servidumbre en cuestión (cfr. D. 8, 1, 20). De esto se deriva que las Inst. 2,3,2 al referirse a las pactiones et stipulationes no se están refiriendo a dos modos de constitución diferentes, sino a uno solo, el pacto y la stipulatio van unidos cuando se trata de la constitución de una servidumbre.

${ }^{32}$ D. 8,1,20 (Iav., 5 Ex post. Lab.): "Quotiens via aut aliquid ius fundi emeretur, cavendum putat esse Labeo per te non fieri, quo minus eo iure uti possit, quia nulla eiusmodi iuris vacua traditio esset. Ego puto usum eius iuris pro traditione possessionis accipiendum esse ideoque et interdicta veluti possessoria constituta sunt". D. 8,6,19 pr. (Pomp., 32 Sab.): "Si partem fundi vendendo lege caverim, uti per eam partem in reliquum fundum meum aquam ducerem, et statutum tempus intercesserit, antequam rivum facerem, nibil iuris amitto, quia nullum iter aquae fuerit, sed manet mihi ius integrum: quod si fecissem iter neque usus essem, amittam". CI. 3,34,3: "Et in provinciali praedio constitui servitus aquaeductus vel aliae servitutes possunt, si ea praecesserint, quae servitutem constituunt: tueri enim placita inter contrahentes debent. quare non ignorabis, si priores possessores aquam duci per praedia prohibere iure non potuerunt, cum eodem onere perferendae servitutis transire ad emptores eadem praedia posse". Véanse, entre los 


\section{La constitución de servidumbres prediales en las "Ordinacions de Sanctaci-} lia”.

Las servidumbres prediales ya habían sido tratadas, en Cataluña, por el "usatge" Omnes causae y en el Recognoverunt proceres, con anterioridad a la aparición de esta colección de costumbres.

Las Ordinacions de Sanctacilia o Consuetuts de la ciutat de Barcelona sobre les servituts de las casas e honors datan de mediados del siglo XIV y constituyen seguramente una recopilación privada de ordenaciones del rey Jaume II -su aparición, de acuerdo a Pella y Forgas, se debe al gran auge que la construcción había ya adquirido en esta época, especialmente la construcción de catedrales ${ }^{33}-$, de cuya redacción se habría ocupado el agrimensor o geómetra Jaume de Sanctacília. Aunque en un principio debían aplicarse a la ciudad de Barcelona, su ámbito de aplicación se extendió a todo el territorio catalán, como consecuencia de las recopilaciones del Derecho de Cataluña, a excepción de Tortosa, que ya disponía de una completa regulación de las servidumbres urbanas en su Llibre de Costum de la ciutat de Tortosa. En los últimos años, se ha ocupado de su estudio el profesor Ribalta ${ }^{34}$.

Centrándonos en la constitución de servidumbres prediales, de acuerdo a las Ordinacions de Sanctacilia, éstas se constituyen por ley, costumbre, pacto, estipulación, prescripción, testamento o por el juez.

La constitución por pacto se deriva de referencias tales como "ab vehi se sie avengut" ${ }^{35}$ y de otras similares que hablan de voluntad o avenirse. Pella y Forgas, en su estudio sobre las Ordinacions relaciona la constitución por pacto con la constitución por promisión (contrato, en términos generales) y parece dar a entender que no considera que sea éste un modo de constitución de las servidumbres -cabe entender que, al igual que decíamos respecto a la regulación de las Siete Partidas, sería necesaria la adquisición de la cuasi-posesión de la servidumbre, pues la sola promisión sólo genera una acción personal que permite reclamar la constitución de la servidumbre en cuestión-. Para Pella i Forgas la repetida mención que se hace, en las Ordinacions, a la "carta" se trataría de referencias a la estipulación, que no es más que el contrato escrito: "avengut ab carta” ${ }^{36}$. Es más, para la prueba de la servidumbre, se estableció conforme al Recognoverunt proceres $^{37}$, que debía

autores modernos: Jordán de Asso y Del Río Ignacio - De Manuel y Rodríguez, Miguel, Instituciones del Derecho civil de Castilla (Madrid, 1792, edición facsímil: Valladolid, Lex Nova, s.d. [pero 1984]), pp. 149 y 170. Asimismo, CoInG, Helmut, cit. (n. 20), pp. 315 ss. Y en cuanto a la adquisición de la cuasi-posesión de las servidumbres, SAVIGnY, Friedrich, Das Recht des Besitzes (Gießen, Heyer, 1803, edición facsímil por Keip, 1997), \$46, p. 421 ss.

${ }^{33}$ Pella i Forgas, Josep, Tratado de las relaciones y servidumbres entre las fincas. Examen especial de las Ordinaciones llamadas de Sanctacilia (Barcelona, 1901), p. 21.

${ }^{34}$ Ribalta i Haro, Jaume, Dret urbanistic medieval de la mediterrània (Barcelona, 2005).

${ }^{35}$ Pragmaticas y altres drets de Cathalunya, libro IV, título $2^{\circ}$, ord. $3^{\mathrm{a}}$.

${ }^{36}$ Se menciona la "carta" en las Ordinacions $2^{\circ}, 31^{\mathrm{a}}, 41^{\mathrm{a}}, 4^{\mathrm{a}}$ y $62^{\mathrm{a}}$.

${ }^{37}$ Cap. 460: "Recognoverunt proceres: Item est consuetudo, quod si illi habent lucernas, non habent instrumentum de lucernisibi habendis, nec aliquam tuitionem, nisi tantum prescriptionem 
recurrirse, entre otros medios, al documento y el "usatge" Affirmantis " $^{38}$ ya reconocía fe probatoria a la carta.

Si observamos el texto de algunas de estas ordenaciones, parece que en muchos de los casos, la mención a la "carta", más que en referencia a la prueba de la existencia de la servidumbre, se refiera a la constitución en sí a través de carta, especialmente en aquellos casos donde no es posible la adquisición de la servidumbre a través de usucapión. Con ello, parece dar a entender que el contrato solía -o como mínimo, podía- recogerse en documento notarial y que, además, parece producirse una confusión entre el acto constitutivo de la servidumbre y el documento que recogía dicho acto por escrito ${ }^{39}$.

\section{CONCLUSIONES}

A la luz de las diversas fuentes que hemos podido consultar, podemos afirmar que el destino que siguió a las pactiones et stipulationes desde la época visigoda hasta producirse la recepción del Corpus iuris civilis está íntimamente relacionado con la transformación que sigue la stipulatio, ya desde finales de la época clásica del Derecho romano.

La huella de las pactiones et stipulationes en la constitución de servidumbres prediales en el Derecho histórico debe ser estudiada, a nuestro entender, no tanto en base a la recepción de la stipulatio del Derecho justinianeo en la Baja Edad Media, como en la impronta que esta pieza del sistema contractual romano fue dejando, a lo largo de los siglos, en la práctica documental notarial.

[Recibido el 2 de julio y a probado el 31 de julio de 2009]

\section{BIBLIOGRAFÍA}

Albertario, Emilio, La protezione pretoria delle servitù, en Filangieri 36 (1912).

ÁlvareZ, Ursicino, Los Derechos provinciales romanos y el problema del Derecho foral español, en Anuario de Derecho Civil 2 (octubre-diciembre, 1948) 1.

ANKUM, Hans A., Les tabellions romains, ancêtres directs des notaires modernes, en Atlas du

Notariat. Le notariat dans le monde. Huit siècles de notariat latin - Quatre décennies d'union internationale, Ars Notariatus XLII (separata).

Arias Bonet, Juan Antonio, Recepción de las formas estipulatorias en la Baja Edad Media.

Un estudio sobre las "promisiones" de las Siete Partidas, en Boletim da Faculdade de

Direito de Coimbra 42 (1967).

triginta annorum, quod si clauserint eas operando ibi, vel alio modo, quod iterum non possunt ibi habere lucernas".

38 "Usatge" "Affirmantis": "Del affirmant es provar, no del negant, e aço per totas cosas sera, en exceptio, e en replicatio, e en altras cosas semblants. Sagrament no es prova, mas en deffalliment de prova, e es donar al reo, o al actor, a aquell que el Jutge coneix effer pus cert, e lo qual creu mes tembre lo jurament. Prova fe fa, o per testimonis, o per cartas, o per arguments, o indicis versemblants: doncs sagrament no es prova".

${ }^{39}$ Pella i Forgas, Josep, cit. (n. 33), pp. 125 ss. 
BIONDI, Biondo, Le servitù prediale nel diritto romano (Milano, 1969).

Caepolla, Bartholomeus, Tractatus de servitutibus, tam urbanorum, quam rusticorum praediorum (Lausana, 1764).

Capogrossi, Luigi, Proprietà e diritti reali. Usi e tutela della proprietà fondiaria nel Diritto romano (Roma, 1999).

Codex Iustinianus (ed. Krüger).

CoING, Helmut, Europäisches Privatrecht (München, 1985).

Codex Theodosianus (ed. Mommsen)

D'ORs, Álvaro, Documentos y notarios en el Derecho romano post-clásico, en Centenario de la Ley del Notariado (Madrid, 1964), I.

FERnándeZ de Buján, Antonio, A propósito del oficio de "tabellio" como jurista práctico en la experiencia jurídica romana, en Liber amicorum Juan Miquel. Estudios romanisticos con motivo de su emeritazgo (Barcelona, 2006).

Ferrini, Contardo, Institutionum Graeca Paraphrasis (reimpresión Aalen, Scientia, 1967).

Fragmenta Vaticana (ed. Baviera).

FranCIOSI, Gennaro, Studi sulle servitù prediali (Napoli, 1967).

FrezZA, Paolo, Appunti esegetici in tema di modi pretori di costituzione di usufrutto e delle servitú prediali, en Studi economico-giuridici dell'Università di Cagliari 22 (1934).

Gaius, Institutiones (ed. Baviera).

Grosso, Giuseppe, Le servitù prediale nel Diritto romano (Torino, 1969).

Iustiniani Digesta (ed. Mommsen).

Iustiniani Institutiones (ed. Krüger).

Jordán de Asso y Del Río Ignacio - De Manuel y Rodríguez, Miguel, Instituciones del Derecho civil de Castilla ( $5^{\text {a }}$ edición, Madrid, 1792, edición facsímil Valladolid, Lex Nova, s.d. [pero 1984]).

KASER, Max, Das römische Privatrecht (2a edición, München, 1975).

KNÜTEL, Rolf, "Stipulatio" und" pacta“, en Festschrift für Max Kaser zum 70. Geburtstag (München, 1976).

KrÜGER, Hugo, Die prätorische Servitut (Münster, 1911).

La Rosa, Franca, "Pactionibus et stipulationibus", en Labeo 40 (1994) 1.

LEVY, Ernst, West Roman Vulgar law. The Law of Property (Filadelfia, 1951).

Linares Pineda, José L., "Stipulatio”, en Materiales para el estudio del Derecho. Derecho romano de "Portal del Derecho" SA/IUSTEL (www.iustel.com), también disponible en los materiales "on line" de la página web del grupo de investigación de la UdG "Història de la ciència jurídica": http://web2.udg.es/hcj.

Maninno, Vincenzo, "Conventio" e "voluntas" nell'operatività delle servitù e come fundamento della "servitus personae", en "Iuris vincula". Studi in onore di Mario Talamanca (Napoli, 2001), V.

Maschi, Carlo Alberto, Contributi allo studio delle servitù pretorie, en Bulletino dell'Istituto di Diritto Romano 41 (1939).

MitTeIs, Ludwig, Reichsrecht und Volksrecht in den östlichen Provinzen des römischen Kaiserreichs (Leipzig, 1891).

NúŃEZ Lagos, Rafael, La estipulación en las Partidas y en el Ordenamiento de Alcalá (Madrid, Real Academia de Jurisprudencia y Legislación, 1950).

PACHECO, Francisco, Las servidumbres prediales en el Derecho histórico español (Lleida, 1991). 
Pella i Forgas, Josep, Tratado de las relaciones y servidumbres entre las fincas. Examen especial de las Ordinaciones llamadas de Sanctacilia (Barcelona, 1901).

Perozzi, Silvio, I modi pretorii d'acquisto delle servitù, en Rivista italiana per le scienze giuridiche 23 (1897).

Pragmaticas y altres drets de Cathalunya.

RABEL, Ernst, $Z u$ den sogennanten prätorischen Servituten, en Mèlanges Girard (Paris, 1923).

Ribalta i Haro, Jaume, Dret urbanistic medieval de la mediterrània (Barcelona, 2005).

Riccoвono, Salvatore, "Dies" e "condicio" nella costituzione della servitù, en Tijdschrift voor Rechtsgeschiedenis 3 (1922).

SAVIGNY, Friedrich, Das Recht des Besitzes (Gießen, Heyer, 1803, edición facsímil por Keip, 1997).

Talamanca, Mario, voz: “Documento e documentazione”, en Enciclopedia del Diritto (Milano, Giuffré, 1964), XIII.

WACKE, Andreas, El pluralismo lingüistico y su reglamentación jurídica en el Imperio Romano, en Seminarios Complutenses de Derecho Romano 11 (1999). 